\title{
ASSOCIATION BETWEEN ADJUSTMENT LATITUDE AND SICKNESS PRESENCE - A PANEL STUDY OF SWEDISH EMPLOYEES
}

\section{GUN JOHANSSON', KLAS GUSTAFSSON², and STAFFAN MARKLUND ${ }^{2}$}

\author{
Karolinska Institute, Stockholm, Sweden \\ ${ }^{1}$ Institute of Environmental Medicine, Unit of Occupational Medicine \\ ${ }^{2}$ Insurance Medicine, Department of Clinical Neuroscience
}

\begin{abstract}
Objectives: This study is analyzing the unexpected reversed or lacking association between high adjustment latitude and sickness presence by examining whether it is due to confounding. Material and Methods: Questionnaires were sent in 2004 and 2005 to a cohort of individuals aged 25-50 years, selected from the Statistics Sweden's register of the Swedish population. Information from 2397 individuals who answered both questionnaires was analyzed by the use of logistic regression analysis. Results: The odds ratio for sickness presence among the individuals with a low adjustment latitude compared to those with high adjustment latitude was 1.7 (range: 1.4-2.2). This increased likelihood was almost entirely unaffected in the analysis of potential confounders. Conclusions: If the reversed association between adjustment latitude and sickness presence does not reflect confounding, it may be due to reporting bias, which may cause problems in research on sickness presence. We argue that more detailed studies are needed to explore the different sources of possible reporting problems.
\end{abstract}

Key words:

Bias, Work place, Sickness behaviour, Questionnaires, Sweden

\section{INTRODUCTION}

Several studies have reported that sickness presence (i.e., attending work despite illness) increases the risk of future poor health and sickness absence [1-4]. Sickness presence is common - studies from the Scandinavian countries show that $50-60 \%$ of employees report attending work when being ill at least twice a year [5-7]. Sickness presence has been shown to increase along with both individual and work-related conditions such as financial problems, poor health, high time pressure, high requirements to attend work and long working hours [6-9]. Workrelated factors seem to be more important than personal circumstances and attitudes [7]. There are also indications that sickness presence is more sensitive to working-time arrangements, in comparison to sickness absence [10]. One work dimension of interest here is the degree to which employees experience freedom to change their work arrangements. The concepts used to study this dimension include adjustment latitude, which describes the opportunities an employee has to adjust work to their health, and control, which describes how much control the employee has over how and when a work task should be performed. However, contrary to expectations, most studies have found that employees with high adjustment latitude or high control at work are less likely to report sickness presence than those who have fewer opportunities to adjust $[2,6,7,9,11-13]$.

Received: May 6, 2014. Accepted: October 21, 2014.

Corresponding author: G. Johansson, Karolinska Institute, Institute of Environmental Medicine, SE-171 77 Stockholm, Sweden (e-mail: gun.johansson@ki.se). 
Sickness presence has been given different definitions, but according to Johns [14] all these definitions include being physically present at work. Sometimes sickness presence is described as good, as it means the employee is not absent, but it has been also described as being at odds with the individual's health and as resulting in less than full productivity of an employee (see also Irvine [15]). According to Johns [14], the most recent conceptions involve an employee turning up to work despite being ill; the concept is thus aimed at capturing behaviour when an individual is having a health problem. Most studies of sickness presence have gathered information through a self-reported question asking whether the individual has gone to work despite illness $[2,4,6,7,11,12,16]$.

The present study focuses on the reversed association between sickness presence and adjustment latitude at work. As stated above, empirical studies indicate that those who cannot adjust their work to reduced health are more likely to attend work than those who can adjust work to their health.

One possible explanation for the reversed association between adjustment latitude and sickness presence is that it is due to confounding, as proposed by Gustafsson [17]. Although most studies have some confounder control, different studies use different confounders, and few have tried to include a wider range of conditions that may influence sickness presence or adjustment latitude.

At least 4 groups of confounding conditions may be associated with both adjustment latitude and sickness presence, and hence, may cause the reversed association. These potential groups of confounders encompass both individual and work-related conditions. Taking all 4 groups together, the confounding problem may be scrutinized through an extensive confounder control that has only partly been carried out in the previous studies.

The 1st group of potential confounders concerns resources that may determine the need to be present at work while being sick, such as poor health and poor financial situation. Individuals with good health and good financial situation are less likely to report sickness presence than those with poor health or poor finances [9,18], which may reflect a lesser need to be present at work while being sick. Those with high adjustment latitude at work may simultaneously have better health and better financial situation than those with low adjustment attitude. The need to be present despite being sick is therefore likely to be lower among those with high adjustment latitude.

Sickness presence is only one possible strategy to handle illness among employees. The 2nd group of potential confounders concerns alternative strategies to handle illness, such as possibility to take compensatory leave, vacation time and sickness absence. However, several studies have reported a positive association between sickness absence and sickness presence $[6,7,18]$, which violates the assumption of sickness absence being an alternative strategy to sickness presence. Despite this, we test the alternative strategy assumption here. Conditions in and outside work may determine the availability of different strategies to handle illness [9]. Having high adjustment latitude may coincide with high availability of these alternative strategies, reducing the need for sickness presence.

Other work conditions that are related to sickness presence and adjustment latitude constitute the 3rd group of possible confounders. Conditions that may affect sickness presence include: whether work tasks will continue to accumulate while the employee is away, whether the employee's colleagues will have to take over his/her job tasks, or whether important activities such as medical treatment or lessons will have to be cancelled. Such negative consequences seem to act as attendance requirements, and make the individual attend work when being ill rather than be absent [6,9]. The lower sickness presence among those with high adjustment latitude may be a result of these individuals also having higher attendance requirements at work than those with low adjustment latitude. Job demands in general may also differ. Deery et al. [19] have 
reported that high job demands were associated with high sickness presence.

The 4th group of possible confounders concerns differences in personal attitudes. Johns [14] has proposed that a theory of presenteeism and absenteeism should encompass personal conditions such as work attitudes. Attitudes such as treating work as home and being over-committed to work have been shown to lead to higher levels of sickness presence [7]. It is possible that one way these attitudes exert influence on sickness presence is through the feeling of loyalty. Employees with high and low adjustment latitude may differ in loyalty towards work, which affects their behaviour when ill.

\section{Aim of the study}

The aim of this study was to explore whether the unexpected negative association between adjustment latitude and sickness presence changes when a range of confounders, such as: health, financial situation, alternative strategies when being ill, sickness absence, attendance requirements at work and loyalty to work, are introduced.

\section{MATERIAL AND METHODS}

\section{Sample and procedure}

A cohort of 5009 individuals, aged 25-50 years, was created in 2004 from the Statistics Sweden's register of the Swedish population. Of these, 34 were excluded as they did not belong to the population. In 2004, the remaining 4975 individuals were asked to take part in an initial telephone interview; 3579 (71.9\%) agreed to this. In the 2nd step, the employed individuals ( $\mathrm{N}=3034)$, who took part in the telephone interview, were sent a questionnaire, of which 2493 copies $(82.2 \%)$ were returned. In 2005, the individuals in the cohort were again invited to a telephone interview, and 3513 agreed to take part in it. Of these, 3011 were employed and received a questionnaire nearly identical to the one sent out the year before. The study population for the present study consisted of those individuals who answered the questionnaire [20] in both years $(\mathrm{N}=2397$; $54 \%$ women; age - mean: 37.2 years, standard deviation: 7.2 years).

\section{Data}

Sickness presence

Self-reported sickness presence was measured using the question "Have you, in the past 12 months, gone to work despite feeling that you really should have taken sick leave because of your state of health?" [18]. The response options were as follows: no, never; yes, once; $2-5$ times; more than 5 times; and have not been sick during the past 12 months. In the analysis, the answers "no, never" and "yes, once" were merged with each other, and "2-5 times" and "more than 5 times" were also merged with each other. Test-retest reliability for this question has been tested by Demerouti et al. [21], who have reported a value of 0.58 $(p<0.01)$ or greater for 6 -month and 12-month intervals.

\section{Adjustment latitude}

Adjustment latitude was measured in the 2004 questionnaire using the question "What opportunities do you have for adjusting your work if you do not feel well?". The respondents were asked whether they could adjust their work in any of the 7 ways: doing only the necessary work and postponing the rest; choosing among work tasks; getting help from one's colleagues; working at a slower pace than usual; taking longer breaks; shortening the working day; and postponing the work and going home. The participants answered on a 4-point scale (always, most of the time, mostly not, never), and the responses were summed to create an index ranging from 0 to 7 . The distribution was dichotomized into groups classified as high (4-7) and low (0-3) [22].

\section{Potential explanatory confounders}

General self-rated health was measured in the 2004 questionnaire using the question "How do you rate your 
general state of health?". The original 5-point scale was dichotomized into: very good / rather good ("good") and variable / rather poor / very poor ("poor").

Vacation time/compensatory leave [23] was measured in the 2005 questionnaire using the question "Have you, in the past 12 months, taken vacation time or compensatory leave instead of reporting sick when you felt sick?". The response options were as follows: no, never; yes, once; 2-5 times; more than 5 times; and have not been sick during the past 12 months. In the analysis, the answers "no, never" and "yes, once" were merged with each other, just like the answers "2-5 times" and "more than 5 times."

Information on sickness absence was gathered from the 2005 questionnaire via the question "How many days in the past 12 months were you off work due to sickness (sick leave, receiving health care, under medical treatment, or under investigation)?". The response options were as follows: none, less than a week, 1-2 weeks, 2-4 weeks, 1-3 months, and more than 3 months. The variable was dichotomized into "less than one week" and "one week or more." Voss et al. [24] have found good agreement between the self-reported and registered information on sickness absence.

Information on financial situation [25] was collected in 2004 by asking whether the respondent could raise 14000 Swedish crowns (approx. 1500 euros) within a week. Four response options were given, i.e., yes, always; yes, most of the time; no, mostly not; and no, never. A dichotomy was obtained by merging the 2 "yes" answers and the 2 "no" answers.

Attendance requirements [9] at work were captured in the questionnaire from 2004 by the following 3 questions: "Imagine a situation where you need to be off sick for 1 or 2 days:"

1. Will your work be done by someone else?

2. Will your work be left for you to do when you return?

3. Might some of your work remain undone?

The 4 response alternatives for the 3 questions were: always, mostly, mostly not and never. The 1st question was scored with: always -1 point, mostly -2 points, mostly not -3 points, and never -4 points. On the other 2 questions, the points given were reversed. Scores were summed to an index ranging from 3 to 12 . A median split was used in the analysis, with those scoring 3-7 considered to have low attendance requirements and those scoring 8-12 considered to have high attendance requirements.

Job demands were measured using a 4-item index concerning work intensity, pressure, conflicting demands and emotions, based on work by Karasek and Theorell [26]. The information was collected in 2004. The respondents answered on a 4-point scale (always, most of the time, mostly not, and never). Cronbach's $\alpha$ was 0.61 .

Information on loyalty was collected through 4 questions in the 2004 questionnaire. The questions were aimed at capturing loyalty that demonstrated pride in and support for the organization [27]:

1. I am proud to work in my company/organization.

2. I am willing to work harder than necessary to contribute to my company's / organization's success.

3. I am engaged in my present job and regard myself as important in a meaningful organization.

4. I only care for my work tasks and I am not engaged in my employer or the work place.

The participants could reply on a 5-point scale ranging from "do not agree at all" (1) to "totally agree" (5). Scores on question 4 were reversed, and scores on all questions were then summed resulting in an index ranging from 4 to 20. The internal consistency of the scale can be considered good (Cronbach's $\alpha=0.76)$. The index was dichotomized at the median into low (4-14) and high (15-20).

Information on self-rated health, financial situation, attendance requirements, job demands and loyalty was collected from the questionnaire in 2004, while information on sickness absence, vacation time/compensatory leave and the outcome (sickness presence) was collected from the questionnaire in 2005. The reason for using 
data from 2005 for these latter 3 dimensions was that they all captured the individual's behaviour in the past 12 months.

\section{Other confounders}

Age, gender and socio-economic position in 2005 were also used as confounders. Age was treated as a continuous variable.

Socio-economic position [25] was derived from the individual's occupation and employment status, and was broken down into 3 categories: blue collar workers, white collar workers and professionals.

\section{Analyses}

The likelihood of reporting sickness presence at least twice per year compared to never or once per year in 2005 among the groups reporting different levels of adjustment latitude in 2004 was assessed by computing odds ratios (ORs) in a binomial logistic regression analysis. This method handles categorical outcome variables with 2 values.

First, the association between adjustment latitude and sickness presence was assessed in an analysis stratified by potential predictors in crude models and a model adjusted for gender, age and socio-economic position.

Second, the contribution of all potential predictors to the association between adjustment latitude and sickness presence was assessed blockwise in the 4 confounder groups: resources (health and finances), alternative strategies (compensatory leave/vacation and sickness absence), work (attendance requirements and job demands) and personal (loyalty).

Third, the unique and joint contributions of these blocks were assessed. The contribution of these blocks to the association between adjustment latitude and sickness presence was also adjusted for age, gender and socio-economic position. Version 20 of the SPSS software package was used in the analyses.

\section{RESULTS}

Among those with low adjustment latitude (0-3 opportunities), 56\% reported sickness presence at least twice during the previous year. The comparable figure for those with high adjustment latitude (4-6 opportunities) was $42 \%$ (Table 1 ).

The relationships between potential confounders and sickness presence and adjustment latitude, respectively are shown in Table 2. Sickness presence at least twice per year occurred in $81 \%$ of those reporting poor health and $87 \%$ of those taking vacation or compensatory leave at least twice per year (Table 2); the corresponding figures for those reporting good health or taking vacation time/compensatory leave less often were $54 \%$ and $53 \%$. Sickness presence at least twice per year was also higher among those reporting sickness absence of more than a week ( $70 \%$ vs. $52 \%$ among those reporting less) and those reporting high demands $(63 \%)$. It was slightly higher among those stating they could raise 14000 Swedish crowns within a week (59\%) in comparison to those who said they could not do it (56\%), and among those reporting high attendance requirements

Table 1. Sickness presence in 2005 in the study group in relation to adjustment latitude in 2004

\begin{tabular}{|c|c|c|c|}
\hline \multirow[t]{2}{*}{ Adjustment latitude in 2004} & \multicolumn{3}{|c|}{$\begin{array}{c}\text { Sickness presence in } 2005 \\
(\mathrm{~N}=2397) \\
{[\mathrm{n}(\%)]}\end{array}$} \\
\hline & never/once & twice or more & none \\
\hline Low (0-3 times) & $44(229)$ & $56(291)$ & $17(146)$ \\
\hline High (4-7 opportunities to adjust) & $58(437)$ & $42(320)$ & $9(52)$ \\
\hline
\end{tabular}


Table 2. Sickness presence in 2005 and adjustment latitude in 2004 in the study group in relation to the potential confounders

\begin{tabular}{|c|c|c|c|c|}
\hline \multirow[t]{2}{*}{ Variable } & \multicolumn{2}{|c|}{$\begin{array}{c}\text { Sickness presence } \\
\text { in } 2005 \\
(\mathrm{~N}=2042) \\
{[\mathrm{n}(\%)]}\end{array}$} & \multicolumn{2}{|c|}{$\begin{array}{c}\text { Adjustment latitude } \\
\text { in } 2004 \\
(\mathrm{~N}=1681) \\
{[\mathrm{n}(\%)]}\end{array}$} \\
\hline & never/once & twice or more & $\begin{array}{c}\text { low } \\
(0-3 \text { times })\end{array}$ & $\begin{array}{c}\text { high } \\
\begin{array}{c}\text { (4-7 opportunities } \\
\text { to adjust) }\end{array} \\
\end{array}$ \\
\hline \multicolumn{5}{|l|}{ Health } \\
\hline good & $46(704)$ & $54(815)$ & $48(684)$ & $52(739)$ \\
\hline poor & $19(55)$ & $81(228)$ & $64(164)$ & $36(93)$ \\
\hline \multicolumn{5}{|l|}{ Financial situation } \\
\hline can fix & $40(450)$ & $59(671)$ & $50(448)$ & $50(443)$ \\
\hline can not fix & $44(231)$ & $56(294)$ & $50(223)$ & $50(222)$ \\
\hline \multicolumn{5}{|l|}{ Vacation/compensation } \\
\hline never/once & $47(797)$ & $53(896)$ & $52(560)$ & $48(513)$ \\
\hline twice or more & $13(40)$ & $87(262)$ & $51(107)$ & $49(103)$ \\
\hline \multicolumn{5}{|l|}{ Sickness absence } \\
\hline$\leq 1$ week & $48(660)$ & $52(719)$ & $48(480)$ & $52(516)$ \\
\hline$>1$ week & $30(199)$ & $70(459)$ & $57(238)$ & $43(178)$ \\
\hline \multicolumn{5}{|c|}{ Attendance requirements } \\
\hline low & $44(419)$ & $56(532)$ & $55(424)$ & $46(354)$ \\
\hline high & $39(383)$ & $61(596)$ & $47(423)$ & $53(476)$ \\
\hline \multicolumn{5}{|l|}{ Job demands } \\
\hline low & $45(495)$ & $55(602)$ & $53(587)$ & $47(517)$ \\
\hline high & $37(212)$ & $63(365)$ & $42(229)$ & $58(318)$ \\
\hline \multicolumn{5}{|l|}{ Loyalty } \\
\hline low & $43(260)$ & $57(339)$ & $50(245)$ & $50(243)$ \\
\hline high & $39(278)$ & $61(439)$ & $52(304)$ & $48(285)$ \\
\hline
\end{tabular}

(61\%) and high loyalty (61\%) in comparison to those reporting such values as low (56\% and 57\%, respectively).

The proportion of reporting low adjustment latitude was higher among those with poor health (64\%) than among those with good health (48\%), and higher among those with more than a week's worth of sickness absence (57\%) than among those with less such absence (48\%). It was also higher among those with low attendance requirements $(55 \%)$ than among those with high such requirements
(47\%), and higher among those with low job demands (53\%) than among those with high such demands (42\%). There were no or very small differences in the reported adjustment latitude with regard to financial situation, vacation/compensatory leave and loyalty.

In the crude model, the higher likelihood for 2 or more occurrences of sickness presence among those with low adjustment latitude was evident in almost all the groups stratified by potential confounders (Table 3). An exception 
Table 3. Likelihood to report sickness presence twice or more/year compared to once or never/year among those having low adjustment latitude stratified by the potential confounders

\begin{tabular}{|c|c|c|c|}
\hline Variable & Adjustment latitude & $\begin{array}{c}\text { Crude } \\
{[\mathrm{OR}(95 \% \mathrm{CI})]}\end{array}$ & $\begin{array}{c}\text { Adjusted }^{1} \\
{[\text { OR }(95 \% \mathrm{CI})]}\end{array}$ \\
\hline \multicolumn{4}{|l|}{$\begin{array}{l}\text { Resourses } \\
\text { health }(\mathrm{N}=1277)\end{array}$} \\
\hline \multirow[t]{2}{*}{ good } & low & $1.5(1.2-2.0)$ & $1.5(1.1-1.9)$ \\
\hline & high & 1 & 1 \\
\hline \multirow[t]{2}{*}{ poor } & low & $2.6(1.3-5.2)$ & $2.5(1.2-5.0)$ \\
\hline & high & 1 & 1 \\
\hline \multicolumn{4}{|l|}{ financial situation $(\mathrm{N}=1017)$} \\
\hline \multirow[t]{2}{*}{ can fix 1400 euro } & low & $1.5(1.2-2.0)$ & $2.0(1.4-2.7)$ \\
\hline & high & 1 & 1 \\
\hline \multirow[t]{2}{*}{ can not fix 1400 euro } & low & $1.6(0.9-2.8)$ & $1.2(0.8-1.9)$ \\
\hline & high & 1 & \\
\hline \multicolumn{4}{|l|}{ Alternative strategies } \\
\hline \multicolumn{4}{|c|}{ compensation leave/vacation $(\mathrm{N}=781)$} \\
\hline \multirow[t]{2}{*}{ never/once } & low & $1.7(1.4-2.2)$ & $1.6(1.3-2.1)$ \\
\hline & high & 1 & 1 \\
\hline \multirow[t]{2}{*}{ twice or more } & low & $3.0(1.2-7.5)$ & $2.8(1.1-7.3)$ \\
\hline & high & 1 & 1 \\
\hline \multicolumn{4}{|l|}{ sickness absence $(\mathrm{N}=1275)$} \\
\hline \multirow[t]{2}{*}{$\leq 1$ week } & low & $1.7(1.3-2.2)$ & $1.5(1.2-2.0))$ \\
\hline & high & 1 & 1 \\
\hline \multirow[t]{2}{*}{$>1$ week } & low & $1.7(1.2-2.3)$ & $1.7(1.1-2.7)$ \\
\hline & high & 1 & 1 \\
\hline \multicolumn{4}{|c|}{$\begin{array}{l}\text { Work } \\
\text { attendance requirements }(\mathrm{N}=1275)\end{array}$} \\
\hline \multirow[t]{2}{*}{ high } & low & $1.8(1.3-2.5)$ & $1.6(1.0-2.5)$ \\
\hline & high & 1 & 1 \\
\hline \multirow[t]{2}{*}{ low } & low & $1.7(1.2-2.4)$ & $1.5(1.1-1.9)$ \\
\hline & high & 1 & 1 \\
\hline \multicolumn{4}{|l|}{ job demands $(\mathrm{N}=1242)$} \\
\hline \multirow[t]{2}{*}{ high } & low & $1.4(1.1-1.9)$ & $1.2(0.8-1.8)$ \\
\hline & high & 1 & 1 \\
\hline \multirow[t]{2}{*}{ low } & low & $2.2(1.5-3.4)$ & $2.0(1.2-3.5)$ \\
\hline & high & 1 & 1 \\
\hline \multicolumn{4}{|l|}{$\begin{array}{l}\text { Personal } \\
\quad \text { loyalty }(\mathrm{N}=810)\end{array}$} \\
\hline \multirow[t]{2}{*}{ high } & low & $1.8(1.2-2.7)$ & $1.7(1.1-2.5)$ \\
\hline & high & 1 & 1 \\
\hline \multirow[t]{2}{*}{ low } & low & $1.8(1.2-2.7)$ & $1.6(1.1-2.5)$ \\
\hline & high & 1 & 1 \\
\hline
\end{tabular}

$\mathrm{N}$ - number of respondents; OR - odds ratio; $\mathrm{CI}$ - confidence interval.

${ }^{1}$ Adjusted for age, gender and socio-economic position. 
Table 4. Likelihood to report sickness presence twice or more/year compared to once or never/year among those having low adjustment latitude with regard to the potential confounders

\begin{tabular}{llccc}
\hline \multicolumn{1}{c}{ No. } & \multicolumn{1}{c}{ Variable } & $\begin{array}{c}\text { Respondents } \\
(\mathrm{N}=2397) \\
{[\mathrm{n}]}\end{array}$ & $\begin{array}{c}\text { Model 1 } \\
{[\text { OR (95\% CI)] }}\end{array}$ & $\begin{array}{c}\text { Model 2 } \\
{[\text { OR (95\% CI)] }}\end{array}$ \\
\hline 1 & crude & 1277 & $1.7(1.4-2.2)$ & $1.6(1.3-2.1)$ \\
2 & $1+$ SRH, financial situation & 1017 & $1.7(1.3-2.2)$ & $1.6(1.2-2.1)$ \\
3 & $1+$ compensation leave/vacation, sickness absence & 1253 & $1.8(1.4-2.2)$ & $1.7(1.3-2.1)$ \\
4 & $1+$ attendance requirements, job demands & 1233 & $1.4(1.1-1.8)$ & $1.4(1.1-1.8)$ \\
5 & $1+$ loyalty & 810 & $1.8(1,4-2.4)$ & $1.6(1.2-2.2)$ \\
6 & $1+2+3+4+5$ & 704 & $1.5(1.1-2.1)$ & $1.3(0.9-1.7)$ \\
\hline
\end{tabular}

${ }^{1}$ Adjusted for sex, age and socioeconomic position. Other abbreviations as in Table 1.

was among those who reported being unable to raise 14000 Swedish crowns within a week, where the association did not reach a significance level. Those reporting poor health and those that twice or more a year took compensation leave or vacation to handle illness had a high likelihood to be sick present if they had low adjustment latitude compared to high. However, the confidence intervals were wide and overlapping the interval among other groups. There were hardly any changes in the adjusted model where age, sex and socio-economic positions were controlled for (Table 3). The crude reversed association between adjustment latitude and sickness presence was affected surprisingly little by each of the potential confounders, either blockwise or together. The same was true for the adjusted OR (Table 4). Odds ratios varied between 1.3 and 1.8 and reached statistical significance in all the models apart from the fully adjusted model.

\section{DISCUSSION}

The present study showed that the introduction of confounders had very little effect on the reversed relationship between sickness presence and adjustment latitude. Neither health, financial situation, alternative forms of leave, sickness absence, attendance requirements, job demands nor loyalty to work changed the original odds ratios significantly. Thus, confounding could not explain the reversed association between sickness presence and adjustment latitude in this study.

To our knowledge, this is the 1st study aiming at systematical exploitation of the unexpected reversed association between adjustment latitude and sickness presence. However, some of the confounders tested here have also been analyzed as confounders in previous studies of the association between adjustment latitude or control and sickness presence. Johansson and Lundberg [9] have reported that adjusting for self-reported health, financial situation and attendance requirements led to a loss of significance in the higher likelihood of frequent sickness presence among those reporting low adjustment latitude compared to those who reported high adjustment latitude. Aronsson and Gustafsson [6] have found a significantly higher likelihood of sickness presence twice or more per year among those with the lowest opportunities to control work pace compared to those with the highest, after adjusting for self-reported health, attendance requirements and financial situation.

\section{Methodological considerations}

The strengths of this study were the relatively large data set and the fact that it was based on a representative sample of the Swedish population. Furthermore, the 2-wave 
cross-sectional design made it possible to control for a large number of potential confounders a year ahead of the outcome in the statistical analysis.

A limitation of this study is that the number of respondents was reduced due to the dropout. The mean age among the dropouts was almost identical to the mean age among the study sample, but the dropouts had a somewhat bigger proportion of men than the studied sample. We do not believe this difference has affected our results. However, the low response rate could have introduced bias, since healthy persons are more likely to participate in the studies than those with health problems. Another limitation is that not all the questions were answered by all the participants, which again reduced the total number of respondents in the multiple logistic regression analysis. Age constituted yet another limitation; the sample comprised employees who were between 25 and 50 years old in 2004. Lack of information regarding people over 50 years of age restricts the opportunities to generalize our results outside the ages of the sample. However, we see no reason why causes for the reversed association would differ between older and younger age groups.

We only had information on the number of times of sickness presence, and not the length of each spell. If these 2 measures do not coincide, one may question whether our measure differentiates between those with high and low sickness presence. However, Leineweber et al. [28] have found a high correlation between the number of days and the number of times of sickness presence. Further, inquiring about sickness presence, sickness absence and alternative leave in the previous 12 months was potentially problematic. The long period of time under consideration could have led to recall bias, which in turn, may have resulted in misclassifications. If such a recall bias exists, it may dilute or change the associations found. If the ability to recall differs between the groups defined by target variables or potential confounders, this may explain the associations found.
Information on target variables and potential confounders was exclusively based on self-reports, and so, there is a risk of common method bias; that is, it is possible that the results reflect the measurement method rather than the construct the measures represent [29]. Such method bias may inflate or deflate the results. If potential confounders in our study share variance with either or both of the target variables, the confounding argument may not have been properly tested. One type of common method bias may be a result of concurrent collecting of data; our longitudinal design allowed us to minimize this by using some information from 2004 and some from 2005.

The study was based on a Swedish sample. As most previous studies on the association between sickness presence and adjustment latitude or control at work have been performed in Sweden, we consider this choice appropriate.

\section{Implications}

According to our results, the reversed association between adjustment latitude and control on the one hand, and sickness presence on the other was not due to confounding. Although confounding cannot be ruled out as an explanation for this reversed association, alternative explanations should be considered.

One such alternative explanation is that the reversed association is due to a reporting bias. This explanation was 1st proposed by Johansson and Lundberg [9], who have suggested that there may be a conceptual confusion between adjustment latitude and sickness presence. For example, an employee with an aching back and high adjustment latitude may only do the most necessary work tasks, working at a pace suited to their health. These employees may be less likely to report sickness presence than the employees with a low adjustment latitude, because the fact that they could adjust their work to their health meant they did not regard themselves as sick. This interpretation has also been suggested by Aronsson et al. [18], Gustafsson [17], and Westerlund et al. [13] in relation to the reversed 
association between control at work and sickness presence, and in addition, it was acknowledged in a well-cited review of sickness presence [14].

Reporting bias may, thus, be the major reason for the reversed association between sickness presence and adjustment latitude. If so, self-reported information on sickness presence will not only reflect behaviour in relation to illness, but also behaviour in relation to work conditions such as adjustment latitude and control at work. This will mean that the numbers reporting sickness presence among those with, for example, high and low adjustment latitude are not proportional to the prevalence of illness in these groups. A higher proportion of those with low adjustment latitude (or low control at work) will report being present when ill in comparison to those with high adjustment latitude (given a comparable illness). Having high adjustment latitude may, thus, affect one's self-diagnosis.

The possible under- and over-reporting described above constitutes a misclassification problem if the construct of sickness presence is intended to capture behaviour during illness. An alternative view is that sickness presence should be defined as attending work with reduced work ability. Vänni et al. [30] have found that perceived work ability may be a robust indicator for assessing the perceived productivity loss. If sickness presence is defined as behaviour in relation to work ability, there may be no "reporting bias." Instead, this may be the "proper" sickness presence to study, as attending a highly adjustable job when being ill may mean that work ability is retained (Johansson and Lundberg, 2004) [9]. This type of "sickness presence" may be less harmful for future health than sickness presence in a less adjustable job, and it may even not affect productivity. Attending work when being ill in a highly adjustable job may thus be "good," as harmful effects from sickness absence are avoided, while it may be at odds with one's health status in a less adjustable job.

Regardless of how sickness presence is defined, the problem of possible reporting bias has to be further studied by analyzing whether the individual takes work conditions into account when reporting being present at work despite illness. The design of such studies will take some thought. One possible strategy is to conduct studies of how individuals with different degrees of health problems consider adjustment latitude when thinking of being sickness present or not. Another strategy for such studies could be to follow a group of individuals over time with a common diagnosis and similar symptoms, with regard to opportunities to adjust work and reported sickness presence. If the reporting bias is at work, we can expect that despite similar symptoms, reporting sickness presence will differ with regard to adjustment latitude. Such a strategy should be supported by interviews with employees with different adjustment latitude, including questions about their reasoning on sickness presence in hypothetical or actual instances of illness [31,32].

\section{CONCLUSIONS}

Our results do not support the interpretation that the reversed association between adjustment latitude and sickness presence is primarily a result of confounding. As confounding did not change the reversed association, it may instead reflect reporting bias. If so, reporting sickness presence reflects individual considerations in relation to both poor health and work conditions. This may distort results in the studies of both causes and consequences of sickness presence.

A practical implication of this is that occupational health services should be aware that reporting sickness presence may reflect behaviour linked to work conditions rather than behaviour linked to a person's present state of illness.

\section{REFERENCES}

1. Taloyan M, Aronsson G, Leineweber C, Hanson LM, Alexanderson K, Westerlund H. Sickness presenteeism predicts suboptimal self-rated health and sickness absence: A nationally representative study of the swedish working population. Plos One. 2012;7(9):1-8, http://dx.doi.org/10.1371/journal.pone.0044721. 
2. Gustafsson K, Marklund S. Consequences of sickness presence and sickness absence on health and work ability: A Swedish prospective cohort study. Int J Occup Med Environ Health. 2011;24(2):153-65, http://dx.doi.org/10.2478/ s13382-011-0013-3.

3. Hansen CD, Andersen JH. Sick at work-a risk factor for long-term sickness absence at a later date? J Epidemiol Comm Health. 2009;63(5):397-402, http://dx.doi.org/10. 1136/jech.2008.078238.

4. Bergstrom G, Bodin L, Hagberg J, Lindh T, Aronsson G, Josephson M. Does sickness presenteeism have an impact on future general health? Int Arch Occup Environ Health. 2009;82(10):1179-90, http://dx.doi.org/10.1007/s00420009-0433-6.

5. Johansen V, Aronsson G, Marklund S. Positive and negative reasons for sickness presenteeism in Norway and Sweden: A cross-sectional survey. BMJ Open. 2014;4(2):e004123, http://dx.doi.org/10.1136/bmjopen-2013-004123.

6. Aronsson G, Gustafsson K: Attendance presenteeism: Prevalence, attendance-pressure factors, and an outline of a model for research. J Occup Environ Med. 2005;47(9):958-66, http://dx.doi.org/10.1097/01.jom.0000177219.75677.17.

7. Hansen CD, Andersen JH. Going ill to work - What personal circumstances, attitudes and work-related factors are associated with sickness presenteeism? Soc Sci Med. 2008;67(6):956-64, http://dx.doi.org/10.1016/j.socscimed.2008.05.022.

8. Johns G. Attendance dynamics at work: The antecedents and correlates of presenteeism, absenteeism, and productivity loss. J Occup Health Psych. 2011;16(4):483-500, http:// dx.doi.org/10.1037/a0025153.

9. Johansson G, Lundberg I. Adjustment latitude and attendance requirements as determinants of sickness absence or attendance. Empirical tests of the illness flexibility model. Soc Sci Med. 2004;58(10):1857-68, http://dx.doi.org/10.10 16/S0277-9536(03)00407-6.

10. Bockerman P, Laukkanen E. What makes you work while you are sick? Evidence from a survey of workers. Eur
J Public Health. 2009;20(1):43-6, http://dx.doi.org/10.1093/ eurpub/ckp076.

11. Leineweber C, Westerlund H, Hagberg J, Svedberg P, Luokkala M, Alexanderson K. Sickness presenteeism among Swedish police officers. J Occup Rehabil. 2011;21(1):17-22, http://dx.doi.org/10.1007/s10926-010-9249-1.

12. Gosselin E, Lemyre L, Corneil W. Presenteeism and absenteeism: differentiated understanding of related phenomena. J Occup Health Psychol. 2013;18(1):75-86, http://dx.doi. org/10.1037/a0030932.

13. Westerlund H, Kivimaki M, Ferrie JE, Marmot M, Shipley MJ, Vahtera J, et al. Does working While III trigger serious coronary events? The Whitehall II study. J Occup Environ Med. 2009;51(9):1099-104, http://dx.doi.org/10. 1097/JOM.0b013e3181b350e1.

14. Johns G. Presenteeism in the workplace: A review and research agenda. J Organ Behav. 2010;31(4):519-42, http:// dx.doi.org/10.1002/job.630.

15. Irvine A. Something to declare? The disclosure of common mental health problems at work. Disabil Soc. 2011;26(2): 179-92, http://dx.doi.org/10.1080/09687599.2011.544058.

16. Janssens H, Clays E, de Clercq B, de Bacquer D, Braeckman $\mathrm{L}$. The relation between presenteeism and different types of future sickness absence. J Occup Health. 2013;55(3): 132-41, http://dx.doi.org/10.1539/joh.12-0164-OA.

17. Gustafsson K. Working conditions, compensatory strategies and recovery. Stockholm: Psykologiska Institutionen; 2008.

18. Aronsson G, Gustafsson K, Dallner M. Sick but yet at work: An empirical study of sickness presenteeism. J Epidemiol Community Health. 2000;54(7):502-9, http://dx.doi. org/10.1136/jech.54.7.502.

19. Deery S, Walsh J, Zatzick C. A moderated mediation analysis of job demands, presenteeism, and absenteeism. J Occup Organ Psychol. 2014;87(2):352-69, http://dx.doi.org/10.1111/ joop.12051.

20. Marklund S, Berntson E, Bolin M, Härenstam A, Ylander J. Changing organisations and work-related health: Technical 
report of methods, sample and design of three studies. Stockholm: National Institute for Working Life; 2006.

21. Demerouti E, Le Blanc PM, Bakker AB, Schaufeli WB, Hox J. Present but sick: A three-wave study on job demands, presenteeism and burnout. Career Dev Int. 2009; 14(1):50-68, http://dx.doi.org/10.1108/13620430910933574.

22. Johansson G. [The illness flexibility model and sickness absence]. Stockholm: Karolinska Institutet; 2007. Swedish.

23. Aronsson G, Gustafsson K. Vacation - Still an issue of workers' protection? An empirical study of vacation and recuperation. Int J Health Serv. 2005;35(1):143-69, http://dx.doi. org/10.2190/W3AG-TMR4-UDG1-8JMG.

24. Voss M, Stark S, Alfredsson L, Vingard E, Josephson M. Comparisons of self-reported and register data on sickness absence among public employees in Sweden. Occup Environ Med. 2008;65(1):61-7, http://dx.doi.org/10.1136/ oem.2006.031427.

25. Sweden S. Living Conditions Surveys 2000. Stockholm: Statistics; 2000.

26. Karasek R, Theorell T. Healthy work: Stress, productivity, and the reconstruction of working life. New York: Basic Books, Inc.; 1990.

27. Niehoff BP, Moorman RH, Blakely G, Fuller J. The influence of empowerment and job enrichment on employee loyalty in a downsizing environment. Group Org
Manage. 2001;26(1):93-113, http://dx.doi.org/10.1177/105 9601101261006.

28. Leineweber C, Westerlund H, Hagberg J, Svedberg P, Alexanderson K. Sickness presenteeism is more than an alternative to sickness absence: Results from the population-based SLOSH study. Int Arch Occup Environ Health. 2012;85(8):905-14, http://dx.doi.org/10.1007/s00420012-0735-y.

29. Podsakoff PM, MacKenzie SB, Lee JY, Podsakoff NP. Common method biases in behavioral research: A critical review of the literature and recommended remedies. J Appl Psychol. 2003;88(5):879-903, http://dx.doi.org/10. 1037/0021-9010.88.5.879.

30. Vanni K, Virtanen P, Luukkaala T, Nygard CH. Relationship between perceived work ability and productivity loss. Int J Occup Saf Ergon. 2012;18(3):299-309.

31. Hansson M, Boström C, Harms-Ringdahl K. Sickness absence and sickness attendance - What people with neck or back pain think. Soc Sci Med. 2006;62:2183-95, http://dx. doi.org/10.1016/j.socscimed.2005.10.002.

32. McKewitt C, Morgan M, Dundas R, Holland WW. Sickness absence and "working through" illness: A comparison of two professional groups. J Public Health Med. 1997;19:295-300, http://dx.doi.org/10.1093/oxfordjournals.pubmed.a024633.

This work is available in Open Access model and licensed under a Creative Commons Attribution-NonCommercial 3.0 Poland License - http://creativecommons.org/ licenses/by-nc/3.0/pl/deed.en. 